\title{
Does Saudi Arabia Benefit From China’s Belt and Road Initiative?
}

\author{
Khaled Mohammed Alqahtani ${ }^{1}$ \\ ${ }^{1}$ School of Business, Shaqra University, Saudi Arabia \\ Correspondence: Khaled Mohammed Alqahtani, School of Business, Shaqra University, 11662 Riyadh, P.O. Box \\ 88058, Saudi Arabia.
}

Received: July 3, 2019

Accepted: December 11, 2019

Online Published: December 12, 2019

doi:10.5430/jms.v11n1p1

URL: https://doi.org/10.5430/jms.v11n1p1

\begin{abstract}
The People's Republic of China and the Kingdom of Saudi Arabia enjoy close and friendly relations and share broad common interests-regardless of their ideological differences, evident in their names. China's Belt and Road Initiative is aimed at developing infrastructure projects and declining transportation costs to interlink cross-border trade deals between China and countries along the routes. The Kingdom of Saudi Arabia, a central hub connecting Asia, Africa and Europe, has been a significant part of the initiative. Moreover, Saudi Arabia is one of the first countries that have responded positively to the Belt and Road Initiative (BRI). The BRI brings China much closer to Saudi Arabia. As BRI's linchpin in the Middle East, dose Saudi Arabia benefit from this initiative? Based on the elaborate analysis of main research question, this study reveals that the BRI offers great potential opportunities for the Kingdom in terms of infrastructure construction, energy cooperation, technology and finance, culture exchange, security and defense. In addition, China could collaborate with Saudi Arabia in a significant number of sectors where Saudi and Chinese strengths are complementary. The deeper Sino-Saudi cooperation can also brighten the prospects for Saudi Vision 2030.
\end{abstract}

Keywords: The Belt and Road Initiative, Saudi Vision 2030, infrastructure construction, energy cooperation, technology support, anti-terrorism

\section{Introduction}

For centuries, the ancient Silk Road from Xi'an provided a two-way link with thriving trade centers as far away as Rome and Malacca. Fast forward to the 21st century, the BRI was announced by China in 2013, aiming to revive the vibrant Silk Road and offer a new platform for multilateral cooperation (Majdalani, 2018). The Kingdom of Saudi Arabia, China's biggest trading partners in the Middle East, plays a key role in the geographic layout of the BRI. Saudi Arabia is located in a unique strategic nexus of three continents: Africa, Asia and Europe. Having established diplomatic ties in 1990, Saudi Arabia and China have seen a good all-around development of the bilateral relationship. Since 2015, China has become Saudi Arabia's the largest trade partner and Saudi Arabia has been one of China's top suppliers for crude oil for many years. The King Salman bin Abdulaziz Al Saud visited China in March 2017 after President Xi Jinping paid a state visit to Saudi Arabia in January 2016. During the King Salman's visit, both countries significantly lifted a bilateral relationship to a comprehensive strategic partnership. Furthermore, Saudi's King Salman signed a number of investment cooperation deals worth 65 billion USD.

For the sake of reforming its heavily oil-dependent economy, the Kingdom of Saudi Arabia announced an ambitious growth strategy-Saudi Vision 2030. This historically strategic reform aims at diversifying the Saudi economy and revenue sources away from petroleum sectors, meanwhile encouraging the participation of private sectors and developing a knowledge-based sustainable economy. On the other hand, the primary objective of China's BRI is to set up the largest economic corridor and business network in the world. Obviously, does Saudi Arabia benefit from China's Belt and Road Initiative? This main inquiry is for research and analysis in this study. To answer this key question, the specific contents of BRI and Saudi Vision 2030 are elaborately discussed. Moreover, the opportunities for Saudi Arabia from China's BRI are also identified.

\section{The Content and Scope of the Belt and Road Initiative}

During the state visits to Kazakhstan and Indonesia in September and October 2013, Chinese President Xi Jinping put forward a cooperation initiative known as the BRI. The BRI, an abbreviation of "the Belt and Road Initiative", refers to jointly build the "New Silk Road Economic Belt" and "21st Century Maritime Silk Road" with countries 
along the Belt and Road.

The BRI is dedicated to the connectivity of Eurasia and the continent of Africa as well as their adjacent oceans, starting from the dynamic East Asia economic circle in the east and entering the prosperous European economic circle in the west. Along the way, many are developing countries and emerging economies indicating the bright future and vast potential of economic growth. In detail, the "Belt" has three directions: from China, through Central Asia and Russia to Europe; Secondly, through Central Asia and the Middle East to the Persian Gulf and the Mediterranean Sea; Thirdly, from China to Southeast Asia, South Asia and the Indian Ocean. On the other hand, the "Road" focuses on two directions. One is to extend from China's coastal ports through the South China Sea to the Indian Ocean and to Europe. Another is from China's coastal ports across the South China Sea to the South Pacific. This is the key direction of One Belt And One Road construction. The BRI adheres to the principles of openness, cooperation and mutual benefits so that it is a win-win way to promote common development and prosperity of European and Asian markets (see Figure 1 below).

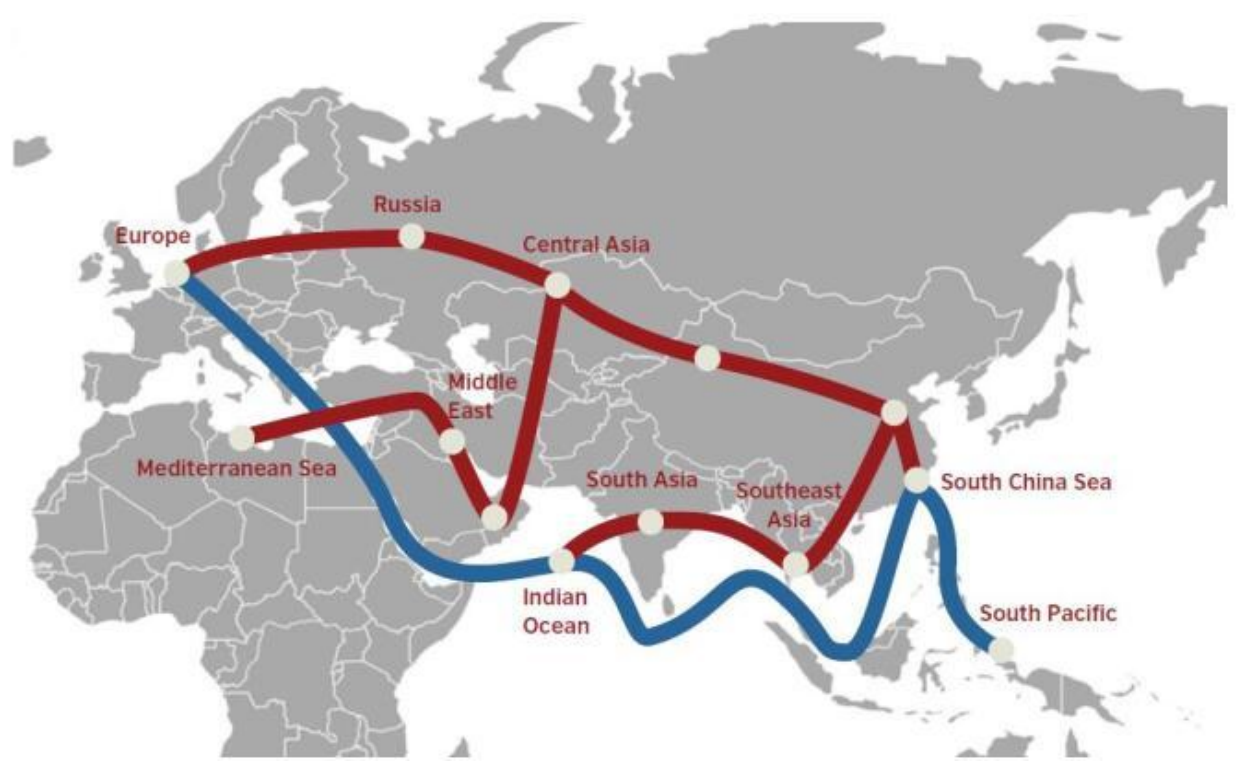

Figure 1. The red routes are the "New Silk Road Economic Belt" and the blue route is the "21st Century Maritime Silk Road"

Encompassing about four billion people (60\% of global population) in over sixty countries, and the total economic amount up to twenty-one trillion USD (40\% of world's GDP), the BRI is regarded as the greatest initiative that China has ever come up with farsighted significance (Magnus, 2015; Wu, 2015).

The BRI aims to achieve five momentous objectives among its constituent nation states: "policy coordination, facilities connectivity, unimpeded trade, financial integration and people-to-people bonds" (Huangfu and Wang, 2015). In detail, the BRI is designed to set up all-dimensional, multi-tiered and composite connectivity networks of Asia, Europe and Africa, and their adjacent seas by strengthening policy communication, road connectivity, trade links, currency circulation, people-to-people connections and cultural exchanges. The connectivity projects of the initiative will help the participants to tighten their economic links, deepen cooperation, tap market potential, increase investment and consumption, create demands and job opportunities, and expand the space for long-term growth. People-to-people exchanges play a critical role in enhancing mutual understanding, trust and respect each other and moving us toward our goal of harmony, peace and prosperity (Xi, 2013). On the other hand, the main focus of BRI is the stimulation in economic development of China by means of raising abroad demands and tapping into some new bazaars in the rest of the world. Additionally, the BRI is conducive to curbing protectionism and preventing the underlying decline in consumer demands in China. By this token, the crucial position of the BRI in achieving the Chinese dream of the great national renewal can not be underestimated.

\section{Economic Adjustment in Saudi Arabia - Saudi Vision 2030}

The Kingdom of Saudi Arabia, a member of G20, is the biggest petroleum exporter in the world and derives around 
$90 \%$ of the government revenue from petroleum. Saudi Arabia has been severely impacted by the declining petroleum prices, since the second half of 2014. Moreover, due to the changes in politics, economy and foreign relations, Saudi Arabia launched "Saudi Vision 2030" in 2016. It consists of a series of reform strategies for the Kingdom's sustainable development. For example, the employment is transforming form dependence on foreign labors such as Indians and Pakistanis to the Saudis. The resources allocation is transforming from government control to the market-based mode. The industrial structures are transforming from over-dominance by petroleum industries to renewable energies such as solar power and new sectors such as tourism. The government budget income is transforming from heavy-reliance on petroleum revenue to more various revenue, including the implementation of tax and the creation of a sovereign wealth fund. The sources of investment are transforming from depending on government investment to attracting more private and foreign investment, including opening Saudi Aramco to private investment through a partial initial public offerings (Chen, 2016). Additionally, the Saudi government intends to decrease in subsidies, empower the private sectors and refocus on small and medium-sized firms by encouraging financial assistance. Lastly, the curricula and standards of Saudi educational institutions from childhood to higher education will be modernized. In brief, the main goal of Saudi Vision 2030 is to stimulate non-petroleum sectors and speed up the diversification of national economy.

The Saudi Vision 2030 stressed its aim in creating a dynastic society, a burgeoning economy and a country with great ambition. As illustrated in Table 1 below, each of these themes is further spilt into several targets designed to be realized by the end of 2030. In general, Saudi will concentrate on its civilians and the Islamic faith for the purpose of achieving a vibrant society. It hammered at the development of education, innovation and entrepreneurship to make a more diversified economy and offered more job posts, further to meet a flowering economy. Furthermore, Saudi will pay attention to responsibility, pellucidity and effectiveness when governing the whole country in a bid to become an ambitious nation.

Table 1. The themes and objectives of Saudi Vision 2030

\begin{tabular}{|c|c|}
\hline Theme & Targets \\
\hline \multirow[t]{6}{*}{ A Vibrant Society } & To increase the number of Umrah visitors from 8 million to 30 million annually \\
\hline & To double the number of Saudi heritage sites registered with UNESCO \\
\hline & To develop three Saudi cities be recognized in the top-ranked 100 cities in the world \\
\hline & $\begin{array}{l}\text { To increase household spending on cultural and entertainment activities inside the } \\
\text { Kingdom from the current level of } 2.9 \% \text { to } 6 \%\end{array}$ \\
\hline & $\begin{array}{l}\text { To increase the ratio of individuals exercising at least once a week from } 13 \% \text { of } \\
\text { population to } 40 \%\end{array}$ \\
\hline & To increase the average life expectancy from 74 years to 80 years \\
\hline \multirow[t]{10}{*}{ A Thriving Economy } & To lower the rate of unemployment from $11.6 \%$ to $7 \%$ \\
\hline & To increase the contributions of SMEs to GDP from $20 \%$ to $35 \%$ \\
\hline & To increase women's participation in the workforce from $22 \%$ to $30 \%$ \\
\hline & $\begin{array}{l}\text { To move from Saudi current position as the 19th largest economy in the world into } \\
\text { the top } 15\end{array}$ \\
\hline & To increase the localization of petroleum and gas sectors from $40 \%$ to $75 \%$ \\
\hline & $\begin{array}{l}\text { To increase the Public Investment Fund's assets, from SAR } 600 \text { billion to over } 7 \\
\text { trillion }\end{array}$ \\
\hline & $\begin{array}{l}\text { To raise from Saudi current position of } 25 \text { to the top } 10 \text { countries on the Global } \\
\text { Competitiveness Index }\end{array}$ \\
\hline & To increase FDI from $3.8 \%$ to the international level of $5.7 \%$ of GDP \\
\hline & To increase the contribution of private sectors from $40 \%$ to $65 \%$ of GDP \\
\hline & $\begin{array}{l}\text { To raise Saudi global ranking in the Logistics Performance Index from } 49 \text { to } 25 \text { and } \\
\text { ensure the Kingdom is a regional leader }\end{array}$ \\
\hline
\end{tabular}


To raise the share of non-petroleum exports in non-oil GDP from $16 \%$ to $50 \%$

\begin{tabular}{|c|c|c|}
\hline \multirow{7}{*}{$\begin{array}{l}\text { An } \\
\text { Nation }\end{array}$} & \multirow[t]{7}{*}{ Ambitious } & To increase non-oil government revenue from SAR 163 billion to SAR 1 Trillion \\
\hline & & To raise the ranking in Saudi Government Effectiveness Index from 80 to 20 \\
\hline & & To increase household savings from $6 \%$ to $10 \%$ of total household income \\
\hline & & To raise the contribution of non-profit sectors to GDP from less than $1 \%$ to $5 \%$ \\
\hline & & To establish zero tolerance for all levels of corruption \\
\hline & & $\begin{array}{l}\text { To boost transparency through expanding online services and improving governance } \\
\text { standards }\end{array}$ \\
\hline & & $\begin{array}{l}\text { To establish the King Salman Program for Human Capital Development and train } \\
\text { over 500,000 government employees in best practices }\end{array}$ \\
\hline
\end{tabular}

UNESCO: United Nations Educational, Scientific and Cultural Organization; KSA: the Kingdom of Saudi Arabia; SMEs: Small and Medium-sized Enterprises; SAR: Saudi Arabian Riyal; FDI: Foreign Direct Investment

Source: Saudi Vision 2030, available at: http://vision2030.gov.sa/en, accessed on August 11, 2018

Through these primary pillars, the Kingdom aspires to capitalize its investment capabilities and create a more sustainable economy with solid foundations. In addition, Saudi Arabia also aims to take advantage of its special strategic location to establish the unique role as an integral driver of global businesses and to connect three continents: Africa, Asia and Europe (Alshuwaikhat and Mohammed, 2017).

\section{Opportunities for Saudi Arabia in China's Belt and Road Initiative}

On one hand, Saudi Vision 2030 prioritizes connectivity and economic integration, which is at the heart of the BRI. The government of Saudi Arabia strives to establish a more favorable investment environment, highly advantageous for Chinese companies to make their way into the markets of Saudi Arabia. This is further conducive to the popularity of the Chinese government's Belt and Road Initiative, and Saudi Arabia becomes a forceful backer of the BRI. On another hand, the kingdom is in sore needs of construction and technology infrastructure in the wake of fast modernization and urbanization. Therefore, under this current situation, China's BRI could help Saudi Arabia to realize Saudi Vision 2030 in terms of infrastructure construction, energy cooperation, technology and finance, culture exchange, security and defense.

\subsection{The Cooperation in Infrastructure Construction and Energy Fields}

The development of infrastructure construction is vital for the growth and prosperity of any nation. The great and scalable infrastructure is a key asset that would ease the flow of goods and commodities very quickly and efficiently. Saudi Arabia focuses on improving the infrastructure construction, which supports the wider integration and interconnection of the Kingdom with regional and international economies. Particularly worth mentioning is that China has a strong strength in the construction of infrastructural facilities. At present, there are more than one-hundred predominant Chinese enterprises in Saudi Arabia involved in different projects or programs related to real estate, communication, railway, roads, bridges, airports, harbors, power stations and other important national projects or programs. These firms bring tremendous benefits to Saudi Arabia and help enhance its cooperation with China under the BRI.

Jeddah, the second biggest city in Saudi Arabia, was seriously damaged by unprecedented rainstorms that killed over 120 people in 2009. Again, Jeddah suffered a severe destruction and 10 people were killed by the storm in 2011. Owing to the lack of flood control system, Jeddah is rather susceptible to the floods. The moment there is a heavy downpour, a blast of water will fall off from the adjacent mountains to the natural river course, and further threaten this city. China Communication Construction Group (CCCG) won the bidding to establish Jeddah City Project for Flood Drainage worth 500 million USD in 2013. A 37 kilometers project crossing the city in three phases was successfully completed after only nine months. In November 2014, Jeddah experienced two torrential rainstorms without any tragic accident happened. As acknowledgement of the outstanding achievement and contribution, the Saudi government sent a commendatory letter to the CCCG for its amazing work.

As another landmark, the Green Dragon metro was built by China Railways Construction Corporation (CRCC) to facilitate traffic of pilgrims in Mecca. The length of this light railway is only 18.25 kilometers, whereas it is the most difficult and complicated line in the world. Because it has the largest capacity to transport thousands of Muslims 
from all over the world within a certain period. By 2018, the CRCC successfully completed running the trains for nine consecutive years with no major safety accidents. At the same time, this project has offered a lot of job opportunities and training courses to the locals (Xinhua $\left.{ }^{(1)}, 2017\right)$.

In the light of the deployment of the BRI, there are an increasing number of agreements between the Saudi government and Chinese investors for further cooperation in the Kingdom's real estate market. For example, the Ministry of Housing in Saudi Arabia and the government of Ningxia Province in China work together to exploit Al-Asfar outskirts in Al-Ahsa region and build 100,000 housing units (Majdalani, 2018). The Chinese investments of infrastructure construction help Saudi Aribia to strengthen its connectivity of less developed areas and integrate the whole nation with wider commercial opportunities.

Concerning energy cooperation, the world's second-largest economy has cemented ties with the world's largest oil exporter under China's BRI. For instance, China North Industries Group Corp signed a framework pact with Saudi Aramco to run a refinery and chemicals complex in northeast China, which marks one of the high-profile agreements signed during China's Belt and Road Forum in 2107. This planned project will be completed at an estimated cost of 10 billion USD, leading to the considerable improvement of refining capacity (Reuters, 2017). In addition, Sinopec and Saudi Basic Industries Corp, which already jointly established a chemical project in Tianjin, also agreed to develop refineries and petrochemicals plants in both China and Saudi Arabia (Blanchard, 2017).

\subsection{Great Potential in Technology and Finance}

Huawei has collaborated with three major communication enterprises in Saudi Arabia-Saudi Telecom Company, Mobily and Zain, providing the best services and latest technologies for the Saudis, such as TDD and LTE networks, the basic GIP 400 networks and the Client Experience Management system. With implementation of the BRI, Huawei has completed $90 \%$ of Saudi government projects in many remote areas during the past several years. There are three offices located in Riyadh, Dammam and Jeddah with over 1000 staff. The Kingdom has become one of the most significant overseas markets for Huawei $\left(\right.$ Xinhua $\left.^{(1)}, 2017\right)$.

In regard to finance cooperation, the Industrial and Commercial Bank of China set up a branch at Riyadh in 2015. This is the first Chinese bank with a retail presence in Saudi Arabia.

\subsection{Great Potential in Cultural Exchange, Security and Defense}

Over the past five years, young delegations from both Saudi Arabia and China have made interchanges for many times. On top of that, the Kingdom is thinking of a way to reach cooperation with Chinese National Museum. Based on the expectation of intriguing tourists from China, the Kingdom will hold more activities.

In terms of security and defense, China and Saudi Arabia are committed to address both the causes and symptoms of extremism and terrorism. In the anti-terrorism sphere, both countries have common understanding about counter-terrorism and the elimination of the origin of terrorism. The two countries are trustworthy and responsible partners to enhance security along the BRI's routes (Xinhua $\left.{ }^{(2)}, 2017\right)$.

\section{Conclusion}

With great complementarity in the industrial structures, in-depth cooperation in infrastructure construction and energy sector are dominating areas of the China-Saudi partnership, and both correspond with the Belt and Road Initiative and Saudi Vision 2030. Due to both common interests, two countries are enhancing their close cooperation in such fields as technology, finance, culture, security and defense. It is noteworthy that China and Saudi Arabia are also expected to intensify mutual cooperation in other aspects, including education, industry and trade.

In a word, China and Saudi Arabia could work together and link "the Belt and Road Initiative" and "Saudi Vision 2030" for mutual benefits. For China, the BRI is a new vehicle to improve its policy of all-around opening and expand overseas direct investment. For Saudi Arabia, the nation is open and cooperative to explore more business opportunities and reap win-win fruits. The BRI is a great chance for the Kingdom to access new markets and attract more foreign direct investment, facilitating the actualization of Saudi Vision 2030. Furthermore, Saudi Vision 2030 is a long-term national development plan and provides a good opportunity for Chinese and Saudi enterprises to participate together for the sustainable benefits of both countries.

\section{References}

Alshuwaikhat, M. H., \& Mohammed, I. (2017). Sustainability Matters in National Development Visions-Evidence from Saudi Arabia's Vision for 2030. Sustainability, 9(3), 408. https://doi.org/10.3390/su9030408

Blanchard, B. (2017). China, Saudi Arabia eye $\$ 65$ billion in deals as king visits. Retrieved from 
https://www.reuters.com/article/us-saudi-asia-china-idUSKBN16N0G9

Chen, M. (2016). Economic Adjustment in Saudi Arabia and the Promotion of "The Belt and Road" Initiative. Study of West Asia, 1(2), 32-48.

Huangfu, P. L., \& Wang J. J. (2015, March 26). How to Play Well the One Belt and One Road Symphony. Liaowang.

Magnus, G. (2015). China Must Prove Silk Road Plan is Serious. Financial Times. Retrieved from http://www.ft.com/intl/cms/s/0/6e8e7f74-f26d-11e4-b914-00144feab7de.html

Majdalani, R. (2018). What is next for Saudi Arabia in light of the deployment of the Belt and Road Initiative. Retrieved from https://www.knightfrank.ae/blog/2018/02/14/what-is-next-for-saudi-arabia-in-light-of-the-deployment-of-the-be lt-and-road-initiative

Reuters. (2017). China's Norinco and Saudi Aramco line up $\$ 10$ billion refinery plan. Retrieved from https://www.reuters.com/article/us-norinco-saudi-refinery/chinas-norinco-and-saudi-aramco-line-up-10-billion-r efinery-plan-idUSKCN18C18S

The Ministry of Foreign Affairs and the Ministry of Commerce of the People's Republic of China. (2015). Vision and Actions on Jointly Building Silk Road Economic Belt and 21st Century Maritime Silk Road. Retrieved from http://en.ndrc.gov.cn/newsrelease/201503/t20150330_669367.html

Wu, J. M. (2015). China to Play a Bigger Role as a World Contributor. China Daily. Retrieved from http://usa.chinadaily.com.cn/opinion/2015-04/20/content_20481447.htm

Xi, J. P. (2013). Promote Friendship between Our People and Work Together to Build a Bright Future. Nazarbayev University, Astana, Kazakhstan, Retrieved from http://www.fmprc.gov.cn/mfa_eng/wjdt_665385/zyjh_665391/t1078088.shtml

Xinhua $^{(1)}$. (2017). Belt and Road" construction projects bring benefits to Saudis. Retrieved from http://www.ecns.cn/2017/05-09/256692.shtml

Xinhua $^{(2)}$. (2017). Belt and Road Initiative helps Saudi Arabia realize 'Saudi Vision 2030': ambassador. Retrieved from http://www.ecns.cn/voices/2017/03-14/249226.shtml 